\title{
Kulturrevolutionen i Boda - ett provokativt historiebruk
}

\section{Av Niklas Ammert}

Den som under sommarhalvåret 2011 färdats längs väg 25 har, då man närmat sig den lilla bruksorten Boda, kunnat läsa banderoller och skyltar med texten Kulturrevolutionen i Boda. Ingen trafikant tror på allvar att det ska bli revolution i Boda eller att ordförande Maos metoder ska tillämpas i de småländska skogarna. Inte heller misstänker någon att arrangörerna i Boda skulle försvara eller rättfärdiga massmord och förföljelser i det kommunistiska Kina för 40 år sedan. Nej, vad det handlar om är att det historiska och laddade begreppet "Kulturrevolutionen” för många människor väcker konnotationer till diktatur, förföljelser, våld och massmord. Våra kunskaper om det förflutna används som en referens då nya företeelser och intryck, liksom då återvinning av gamla in- eller uttryck, kommer i vår väg. Vårt historiska tänkande provoceras och reagerar då ett ord som normalt förknippas med något som vi tar avstånd ifrån plötsligt blir rubrik och slogan för något intresseväckande och positivt. Det förflutna som ständigt finns levande och närvarande i nuet, gör det närvarande och samtidiga till en del av ett större sammanhang, så och i fallet med Kulturrevolutionen i Boda. ${ }^{1}$

I frågan om Kulturrevolutionen leder referenserna till tankar om förföljelser och många människors död. I början av 1960-talet var ordförande Maos ställning i Kina försvagad efter misslyckandena med "det stora språnget". Mao oroades dessutom av hur Sovjetunionen öppnade för en fredlig samexistens med Väst och han menade att revisionism var ett hot mot kommunismen även i Kina. ${ }^{2}$ Ordförande Mao tog initiativ till kulturrevolutionen i syfte att stärka sitt grepp om det kinesiska samhället. Han menade att de intellektuella genom sin relativa frihet, kunde kritisera socialismen och att risken för att kapitalismen skulle återinföras därmed var stor. Med hjälp av radikala intellektuella, som bildade röda garden, skulle man rensa ut det gamla och skapa en ny kultur så att kineserna även i sitt tänkande blev verkliga socialister. ${ }^{3}$ Sinologen Simon Leys beskriver dock kampanjen som helt akulturell:

\footnotetext{
"Det tabula rasa som kulturrevolutionen etablerade inom alla kulturens områden, forskning och kunskap var tänkt att fungera som ett radikalt botemedel för att säkerställa att makten stannade kvar hos en okunnig och knappt läs- och skrivkunnig styrande klass". ${ }^{4}$
}

1 Denna, det osamtidigas samtidighet, är en beskrivning av vårt historiemedvetande som ständigt finns med oss utan att vi tänker på det. Det är genom historiemedvetandet vi orienterar oss i livet med det förflutna, nuet och framtiden närvarande. Se Koselleck, Reinhart, Erfarenhet, tid och historia: Om historiska tiders semantik, Göteborg: Daidalos 2004, s. 150.

2 Hägerdal, Hans, Kinas historia, Lund: Historika media 2008, s. $315 \mathrm{ff}$.

3 Schoenhals, Michael (Ed.), China's Cultural Revolution 1966-1969: not a dinner party, Amonk New York: M.E. Sharpe Inc. 1996, Se även Kiernan, Ben, Blod och jord: Historien om folkmord och utrotning, från Sparta till Darfur, Stockholm: Voltaire Publishing 2010, s. 666-668.

4 Leys, Simon, The Burning Forest, New York: H. Holt 1986. 
I aktionerna misshandlade grupper av rödgardister lärare, man plundrade hem, fördrev cirka 400000 människor från städerna och förstörde 4900 av Kinas knappt 7000 officiellt klassificerade historiska platser. ${ }^{5}$ Partifunktionärer som hade pekats ut som "revisionister” eller "kontrarevolutionärer” tvingades göra offentlig avbön inför vrålande massor. Exilkineser uppger, genom tidskriften China Rights Forum, att uppemot 3 miljoner människor gick en onaturlig död till mötes. ${ }^{6}$ Uppgifter från en exiltidskrift är en partsinlaga och kan ifrågasättas, men antalet offer är sannolikt mycket stort. I Forum för levande historias faktaskrift Brott mot mänskligheten under kommunistiska regimer uppges att mellan 750000 och 1,5 miljoner människor dödades under kampanjen för att "rensa klassleden".?

Efter att den civila förvaltningen i Kina lamslagits, industriproduktionen fallit och ekonomisk kris uppstått, avtog kampanjerna under 1970-talets första år. Kulturrevolutionen upphörde dock inte förrän efter Maos död 1976, då ledarna arresterades och dömdes till långa fängelsestraff.

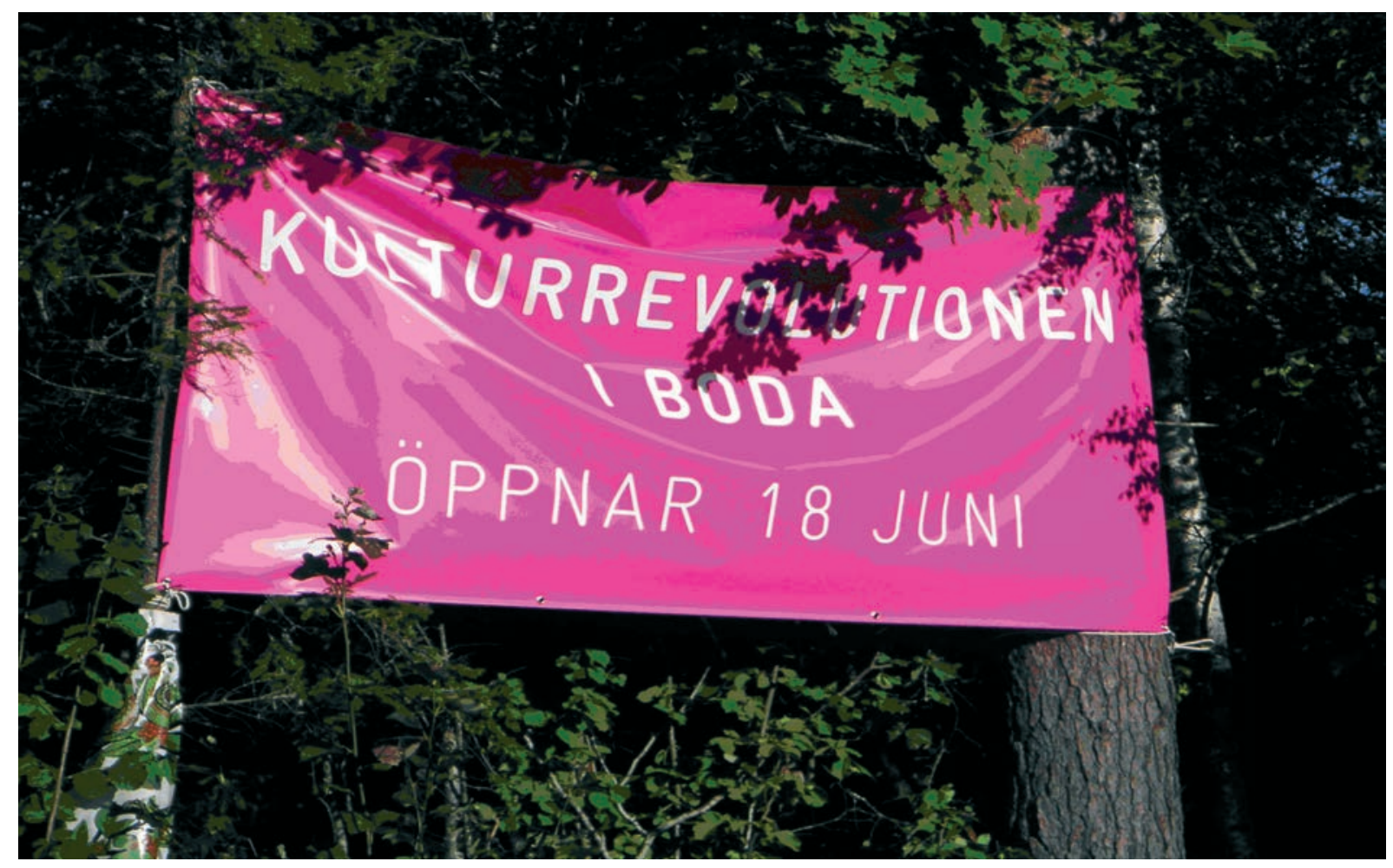

Foto: Niklas Ammert

\section{Avsikt och reaktioner}

Kulturrevolutionen i Boda är benämningen på en satsning att samla designers och konstglashantverkare till den klassiska glasbruksorten Boda mellan Nybro och Emmaboda i Småland. I Boda utvecklade konstnärer som Erik Höglund, Monica Backström och flera andra glaskonsten från 1950-talet och framåt. Traditionen och de genuina miljöerna i Boda ska främja kreativitet och möjliggöra för besökare att studera tillverkningsproces-

5 Brott mot mänskligheten under kommunistiska regimer, 2009, s. 57.

6 China Rights Forum, nr 4, 2005, s. 23.

7 Brott mot mänskligheten under kommunistiska regimer, Stockholm: Forum för levande historia 2009, s. 58. SE också AFP, rapport daterad 1979-02-03. 
sen. Därtill ska konstglas ställas ut och säljas. Det tidigare glasbruket benämns nu The Glass Factory och ska fungera som ett interaktivt museum. Emmaboda kommun står som arrangör tillsammans med Designhouse Stockholm, ${ }^{8}$ ett företag som arbetar med att utveckla form och design. ${ }^{9} \mathrm{Nu}$ beskriver man i ett pressmeddelande från den 18 april 2011 att Boda var platsen för den konstglasrevolution som leddes av konstnärer verksamma i Boda. Här vill man skapa ett centrum för "upplevelse, kreativitet och gränsöverskridande samarbeten kring glas, form och design". ${ }^{10}$ Man vill vidare utmana rådande gränser mellan publik och konstnär, producent och konsument och hyser en förhoppning om att resultatet ska bli revolutionerande. Orden "konstglasrevolution" och "revolutionerande” förekommer således. Designhouse Stockholm presenterar i ett annat pressmeddelande mera utförligt vad Kulturrevolutionen i Boda innebär. I detta beskrivs konstnärer och företag som samarbetar i det tidigare glasbruket i Boda. Värt att notera är att i det femsidiga informationsmaterialet nämns inte ordet kulturrevolution mer än i rubriken. ${ }^{11}$

Av arrangörernas uppgift att döma förefaller det som om man har valt att låta ordet kultur kopplas samman med ordet revolution, vilket här förmodligen ska tolkas som en hastig och omfattande förändring. Att resultatet av de båda ordens sammansättning blev det historiskt och ideologiskt laddade begreppet kulturrevolutionen kan tolkas på två sätt. Den ena tolkningen är att det är ett olyckligt förbiseende och ett misstag att man oreflekterat använder namnet på händelser som kostade människor livet. Den andra tolkningen är att det är ett kommersiellt effektsökeri, i vilket man negligerar de historiska konnotationerna.

Företrädare för Designhouse Stockholm uppger i en intervju att man helt tar avstånd från händelserna i samband med kulturrevolutionen i Kina och att man var beredd på reaktioner och viss kritik. Avsikten med valet av namn på satsningen i Boda var att visa på kulturen som en förändrande kraft i samhället och att väcka intresse. Designhouse Stockholm hänvisar till att konstriktningen Dadaismen använde uttrycket kulturrevolution i sin revolutionära samhällskritik redan vid tiden efter första världskriget. ${ }^{12}$

Valet av namn på satsningen i Boda har väckt viss uppmärksamhet och debatt. I tidningen Östran har företrädare för Moderaterna i Emmaboda beskrivit det som "smaklöst och historielöst”. ${ }^{13}$ Lokalpolitikerna i den borgerliga oppositionen är också starkt kritiska till projektet som sådant och ifrågasätter att lokala företag inte fick vara med och konkurrera vid upphandlingen. Således utgör även kritiken av historiebruket i Boda ett historiebruk i sig, då kritiken mot upphandlingen ramas in av frågan om det är lämpligt att kalla projektet för Kulturrevolutionen. Ytterligare kritik har framförts av en lokal företrädare för Vänsterpartiet som betecknar projektet som ett fiasko och skriver följande:

\footnotetext{
8 http://theglassfactory.se/wp-content/uploads/2011/05/2011-04-11_the-glass-factory.pdf

9 http://www.designhousestockholm.com/

$10 \mathrm{http} / /$ www.mynewsdesk.com/se/pressroom/designhousestockholm/pressrelease/view/open-ensaluhall-foer-design-vet-hut-vaar-egen-studioglashytta-618415 (2011-07-16)

11 www.mynewsdesk.com/se/pressroom/designhousestockholm/.../618415

12 Telefonintervju med Sara Korlén, Information \& Communication Manager, Design House Stockholm, 2011-08-09.
}

13 Östran 2011-06-28 
”Men säg vem skulle bli lockad av något namnmässigt så tråkigt som 'Kulturrevolutionen'. Självklart vet inte gemene man vad det anspelar på och åtminstone jag själv skulle tro att det är något tråkigt för inbitna nördar och därmed skulle jag knappast heller svänga av vägen för att besöka 'attraktionen'"'14

Frågan är vad debattören menar med orden att gemene man inte vet "vad det anspelar på”. Det förefaller som om att han menar att gemene man inte vet vad som försigår i Boda under sommaren 2011. Att ordet kulturrevolution skulle symbolisera systematiska förföljelser och ideologisk utrensning berör han inte över huvud taget.

\section{Historiebruk}

Historia används i en rad olika sammanhang och med olika syften. Många politiker, debattörer och reklammakare ser historien som ett förråd, ur vilket man kan låna förklarande liknelser, hitta material för legitimerande och säljande jämförelser samt hämta avskräckande exempel. Att använda sig av historiskt belastade ord och uttryck är ingalunda unikt eller nytt. I Stockholm finns KGB Bar och Restaurant som dessutom inrymmer Klubb Kalashnikov. ${ }^{15}$ Kopplingarna till KGB stannar sannolikt vid namnet på baren. Ännu en bar med namnet KGB är belägen i New York. Enligt den amerikanske statsvetaren Alexander Motyl finns det där ingenting som förknippar baren med den sovjetiska säkerhetstjänsten. Istället ägnar man sig åt litterära tillställningar med gratis inträde och billiga drinkar. ${ }^{16}$

Avslutningsvis studeras här bruket av det historiska begreppet Kulturrevolution i ljuset av en teoretisk modell som hanterar just hur historia används. Historikern Klas-Göran Karlssons typologi över historiebruk bygger på att historiebruket analyseras och systematiseras med avseende på behov, bruk, brukare och funktion. ${ }^{17}$ Även om typologin ursprungligen är utformad för att på makronivå studera de ryska och sovjetiska samhällena, är den även relevant för att studera historiebruk på mikronivå eftersom parametrarna är centrala aspekter av hur historia kommuniceras. Ett gängse krav på typologier och kategoriseringar är att kategorierna utesluter varandra. Det gör inte kategorierna i Karlssons typologi. Problemet är dock underordnat, om syftet med analysen är att problematisera och förklara den praktiska verkligheten. I den brukas historia sällan endast på ett sätt och i ett syfte. Det är istället så att flera bruk överlappar varandra, påverkas av varandra och påverkar varandra. ${ }^{18}$ När det gäller konkreta sammanhang, torde flera bruk verka parallellt. Historiebruken ska här förstås som analytiska struktureringsprinciper och inte som absoluta kategorier.

14 Östran 2011-07-12

15 Karlsson, Klas-Göran, "KGB bar men inte Gestapo café: Reflexioner kring historiebruk och historiebruksanalys", i Historielärarnas förenings årsskrift 2011, Historielärarnas förening 2011, s. 73-83.

16 Motyl, Alexander, "Why is the 'KGB Bar' possible? Binary, morality and its consequences", i Nationalities Papers, 2010:5, s. 672.

17 Karlsson, Klas-Göran, "Historiedidaktik: begrepp, teori och analys" i Karlsson, Klas-Göran \& Ulf Zander (red.), Historien är nu: En introduktion till historiedidaktiken, Lund: Studentlitteratur 2004, s. $52 \mathrm{ff}$. Typologin är en vidareutveckling av den som finns i Karlsson, Klas-Göran, Historia som vapen: Historiebruk och Sovjetunionens upplösning 1985-1995, Stockholm: Natur och Kultur 1999, s. 57.

18 Aronsson, Peter, "Historia som förebild: Den gode, den onde och den fule", i Aronsson, Peter, (red.), Platser för en bättre värld: Auschwitz, Ruhr och röda stugor, Lund: Nordic Academic Press 2009, s. 13. 
Karlssons typologi innehåller sju olika tänkbara historiebruk: Ett vetenskapligt bruk upptäcker, avtäcker och rekonstruerar det förflutna. Det handlar om att verifiera och tolka händelser och skeenden. Kulturrevolutionen i Boda är inte i något avseende ett exempel på ett sådant bruk av historia. Ett existentiellt bruk handlar om att knyta samman tidsdimensioner och att orientera och förankra människor i historien och därmed i nuet. Ofta handlar det om att samla och spara familjens ägodelar, att släktforska eller att vårda sina fotoalbum. Möjligen kan i det här aktuella exemplet blinkningarna till det förflutna innebära att människor känner igen begreppet kulturrevolutionen och därmed lockas att ta reda på mer. Tolkningen är dock mycket långsökt. Det moraliska bruket söker medvetet att återupptäcka förtryckta grupper eller gamla oförrätter för att nå försoning och rehabilitering. I fallet Boda kan man möjligen tala om ett inverterat moraliskt bruk, eftersom offren för den ursprungliga kulturrevolutionen inte uppmärksammas i det skriftliga informationsmaterialet. Den ursprungliga kulturrevolutionen nämns inte över huvud taget. Ett politisk-pedagogiskt bruk används ofta instrumentellt i undervisning eller av politiska eliter i syfte att illustrera och påverka. Historien blir ett verktyg för att nå och påverka människor. I verksamheten i Boda finns en rad positiva konnotationer som att utveckla unikt konsthantverk, att väcka upp en slumrande bruksbygd och att förändra och förbättra glaskonsttekniken. Då dessa positiva exempel knyts till uttrycket kulturrevolution leder det inte alltför långt att tänka att ordet kulturrevolution även i andra sammanhang kan tolkas på liknande sätt. Alltså används historia för att påverka människor. En liknande funktion har det ideologiska bruket som konstruerar historia för att legitimera en stats existens, för att ta ett exempel. Ickebruket har samma funktion, fast då genom att förtiga eller sudda ut historiska berättelser, traditioner och artefakter ur den offentliga historiekulturen.

Det är sannolikt inte så att ordet Kulturrevolution används för att man på ideologisk grund vill försvara brott mot mänskligheten. Möjligen kan enstaka vålds- och revolutionsromantiker ana en igenkännandets vind från det sena 60-talet, men arrangörerna av kulturrevolutionen i Boda verkar inte hysa sådana tankar. En fråga att resa är dock hur det är möjligt att i Sverige idag använda sig av uttryck och benämningar som förknippas med förföljelser och mord. En närliggande fråga är också varför det är möjligt att använda benämningar som relaterar till eller anspelar på kommunistiska regimer. Att anspela på nazistiska eller fascistiska regimer i det förflutna är fullständigt tabu. Är svaret måhända så enkelt som att den intellektuella vänsterrörelsen legitimerat och ökat acceptansen för symboler, bilder, porträtt och begrepp som hämtas från kommunisktiska diktaturer?

Till sist, skisserar Karlsson ett kommersiellt bruk, vilket i sin tur kan delas upp i två grenar. Den ena grenen använder historia som ett medel för att göra ekonomisk vinst. Ett exempel på det är då företag använder historiska hänvisningar i reklam. Det är uppenbarligen här vi i huvudsak kan placera in Kulturrevolutionen i Boda. Tanken torde vara att kittla besökarens intresse genom att hänvisa till något starkt laddat som de flesta tar avstånd ifrån. När besökare väl har lockats från väg 25 och in till samhället Boda är chansen stor att de handlar, besöker utställningar, köper glass eller äter lunch och därmed är det kommersiella syftet uppnått. Den andra grenen av kommersiellt historiebruk handlar om då kommersiella satsningar och framgångar ökar intresset för historia. Turistboomen i Västergötland, som i spåren 
av Jan Guillous böcker om tempelriddaren Arn, har gjort att fler människor intresserar sig för det historiska arv som finns i form av kyrkor, gårdar, miljöer, forskningsresultat och berättelser. Att trafikanter på väg 25 genom ett besök i Boda skulle intressera sig för kulturrevolutionen i Kina är inte lika säkert.

Att använda uttrycket Kulturrevolution har således väckt visst intresse. Några kritiska debattinlägg har gjorts och författaren till denna text har provocerats och valt att försöka anlysera vad historiebruket innebär. Även om det medfört vissa fördelar för orten Boda, kan bruket av ett tungt värdeladdat historiskt begrepp diskuteras och ifrågasättas. Valet förefaller inte helt och fullt genomtänkt. Vad blir nästa "affärsidé": en outlet med namnet Utrensningarna i Johansfors eller att glasbruket i Orrefors ges en avgörande nystart med namnet Den slutgiltiga lösningen? 